\title{
A comparative study on emotional intelligence and cognitive between successful and unsuccessful entrepreneurs
}

\author{
Paria Karimi, Moien Kloshani and Alireza Bakhshizadeh*
}

Department of Management and Economics, Tabriat Modarres University, Tehran, Iran

\begin{tabular}{l}
\hline A R T I C L E I N F O \\
\hline Article history: \\
Received April 17, 2012 \\
Accepted 11 June 2012 \\
Available online \\
June 12 2012 \\
\hline Keywords: \\
Entrepreneurship \\
Emotional intelligence \\
Factor analysis \\
EQ
\end{tabular}
A B S T R A C T

\begin{abstract}
It has been a long time that researchers are trying to find out on why some people have better mental health than others do and some are more successful than the others are. There are many evidences to believe that having general intelligence does not necessarily yield prosperity and success and it could be accounted up to $20 \%$ of the success, whereas the remaining $80 \%$ is associated with other issues. The present study attempts to perform a comparative study on emotional intelligence and cognitive among successful and unsuccessful entrepreneurs. We adopt a standard test, which includes 133 questions and distribute it between two groups of successful and unsuccessful entrepreneurs in province of Sistan and Balochestan located in south west of Iran. The results of our ANOVA test when the level of significance is five percent reveal that emotional intelligence can substantially impact on the success of entrepreneurs.
\end{abstract}

(C) 2012 Growing Science Ltd. All rights reserved.

\section{Introduction}

There is no doubt that intelligence quotient (IQ) plays an important role on people's future and there are some studies, which indicate that IQ could help succeed. Byington and Felps (2010) explained that IQ testing has become a popular tool for allocating scarce resources in the United States and beyond. IQ-reflective tests are normally implemented in primary and secondary schools to sort students into groups, and by universities and employers to choose between applicants. However, Byington and Felps (2010) argued that the current applications of IQ-reflective tests permit individuals with high IQ scores to receive greater access to developmental resources, enabling them to reach additional capabilities over time, and finally perform their jobs better.

During the past few decades, there have been tremendous efforts on measuring the impact of emotional intelligence on the performance of entrepreneurs (Cojocariu \& Nechita, 2011). Brandstätter (1997) performed an investigation on a random samples from two groups of people. The first group included 255 owners of small and medium sized businesses while the second group was associated with 104 people interested in setting up a private business and both were anonymously asked to

* Corresponding author. Tel: 989132219199

E-mail addresses: abakhshizadeh@ymail.com (A. Bakhshizadeh) 
answer the 16-Personality-Adjective Scales (16PA). Owners also specified how they perceived their past and anticipated future success as entrepreneurs. As expected, owners who were founders were also emotionally more stable and more independent than owners who had taken over their business from parents, relatives, or by marriage. The personality characteristics of people interested in bulding up their own business were almost the same as those of the founders. Besides, independent and emotionally stable business owners were more satisfied with their roles as entrepreneurs and with the success of their business. They preferred internal attributions of the business outcome and were more inclined to expand their business. They concluded that the observed personality differences were supposed to be rather the causes than the effects of entrepreneurship. Emotional intelligence (EI) continues to absorbe a significant amount of interest from researchers who argue that it is an important predictor of health, wellbeing and in particular, work-related outcomes.

Ahmetoglu et al. (2011) explained that many studies highlighted the importance of trait EI in the forecasting of career success. EI prediction on job performance and job satisfaction makes it possible to predict other forms of career success. They investigated whether EI predicts entrepreneurship; that is, whether higher trait EI is associated with entrepreneurial behaviours and entrepreneurial success and whether any impacts of trait EI on entrepreneurship are independent of the personality trait of Core Self-Evaluations, demographic variables, and individual differences in entrepreneurial personal characteristcs. They reported that trait EI could forecast only some entrepreneurial outcomes beyond other variables examined, and with small impact sizes. Therefore, they recommended that individual differences in entrepreneurship result only in part from inter-personal differences in trait EI.

Baron et al. (2012) performed an investigation on dispositional positive affect (DPA) and suggested that there are discrete limits to the benefits conferred by DPA because at very high levels, processes that interfere with specific aspects of cognition, perception, motivation, and self-regulation, operate. Di Fabio and Palazzeschi (2009) performed an investigation on the role of fluid intelligence, personality traits and EI in terms of both ability-based and self-reported in forecasting scholastic success, verifying the existence of incremental validity of EI with respect to fluid intelligence and personality variables. They reported that the influence exercised by fluid intelligence, personality and emotional intelligence on scholastic success, underlining, in particular, the role of EI defined according to the ability-based model.

MacCann et al. (2011) performed an investigation on the relationships between performance measures of EI, coping styles, and academic achievement. They performed two studies to redress this imbalance, in each of these studies, both EI and coping styles were substantially associated with academic achievement. They suggested that better educational outcomes might be achieved by targeting skills relating to emotion management and problem-focused coping. Dacre Pool and Qualter (2012) studied whether it is possible to improve levels of EI and emotional self-efficacy in university students through a teaching intervention. They reported that it is quite possible to increase emotional self-efficacy and some aspects of EI ability.

Nelis et al. (2009) explained that the construct of EI is associated with the individual differences in the perception, processing, regulation, and utilization of emotional information. Based on a controlled experimental design they investigated whether it is possible to increase EI. They asked participants of the experimental group to receive a brief empirically-derived EI training while control participants continued to live normally. Their finding showed a substantial increase in emotion identification and emotion management capabilities in the training group. These findings explain that EI can be improved and open new treatment avenues. Austin et al. (2007) investigated an associations of Machiavellianism (Mach) with self-report and performance EI and with personality and reported that high Machs endorse emotionally-manipulative behavior.

\section{The proposed method}

The proposed study of this paper considers the following two main hypotheses, 
1. There is a relationship between successful entrepreneurs' EI and their success.

2. There is a relationship between unsuccessful entrepreneurs' EI and their success.

There are also some sub-hypotheses associated with this study, which are as follow,

1. There is a relationship between entrepreneurs' cognitive intelligence (CI) and their success.

2. There is a relationship between entrepreneurs' cognitive intelligence (CI) and their failure.

3. There is a relationship between entrepreneurs' EI and their success.

4. There is a relationship between entrepreneurs' EI and their failure.

The independent variable is considered as EI and the primary objective of this survey is to see whether there is any change on the success of an entrepreneur as his/her EI increases. The dependent variable is the level of success among entrepreneurs. Fig. 1 shows details of our survey.

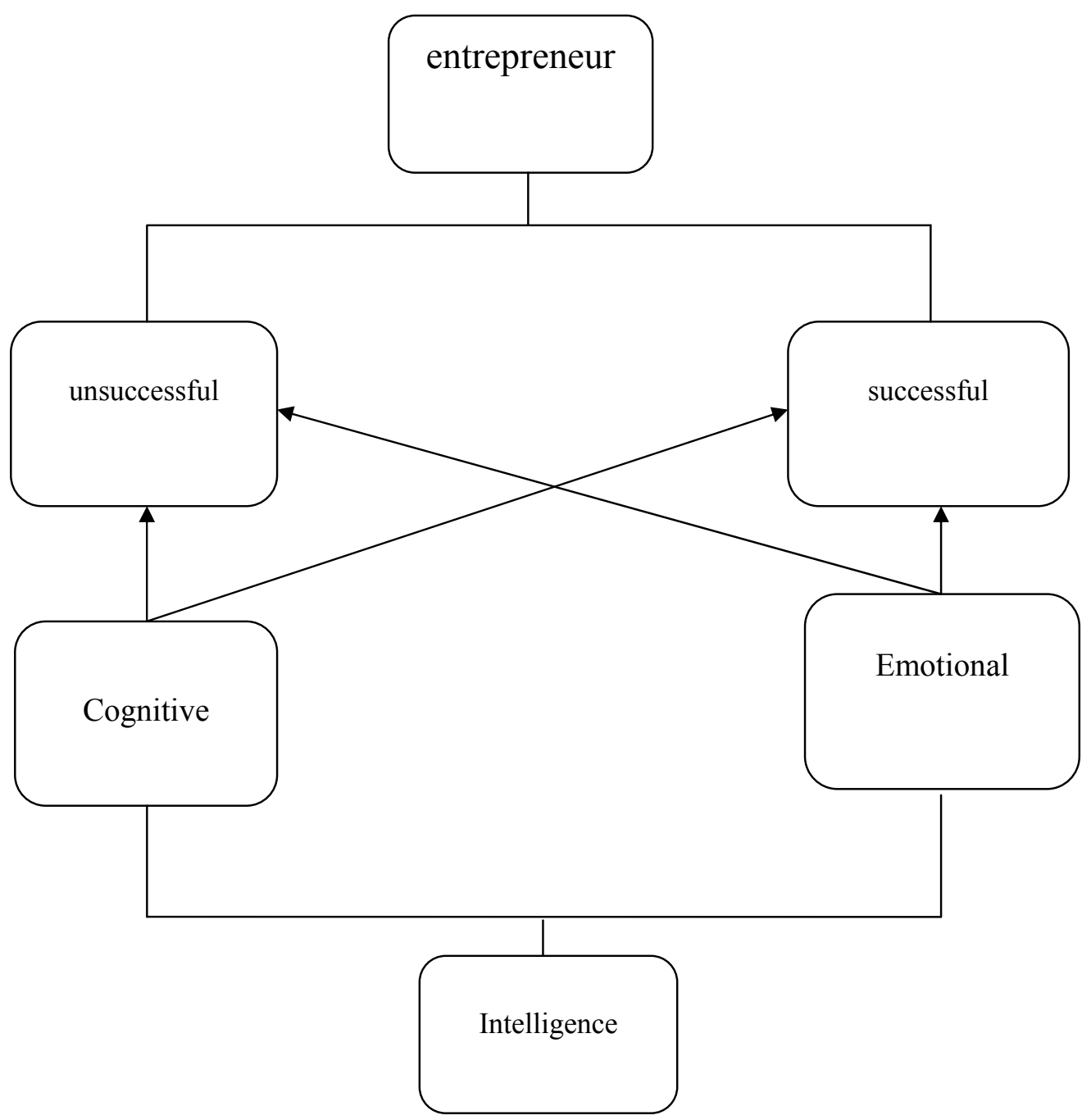

Fig. 1. Framework of the proposed study

The present study is performed on among entrepreneurs who were living in province of Sistan and Balochestan located in south west of Iran. The study uses the following formula to calculate the sample size, 


$$
\mathrm{n}=\frac{\mathrm{z}^{2} \sigma^{2}}{\mathrm{~d}^{2}}=\frac{(1.3)^{2}\left(\frac{1}{2}\right)^{2}}{10 \%^{2}} \cong 42 .
$$

As we can observe, we need 42 questionnaires to make sure that the error term remains less than 10 percent. The proposed study chooses 21 unsuccessful and 21 successful entrepreneurs and distributes the questionnaires among them. Note that the term unsuccessful is used for those entrepreneurs whose plans were either failed or the government did not provide any support for them.

\subsection{Validity and reliability of questionnaire}

We have used a standard questionnaire consists of 133 questions and we believe it maintains a standard form, where it has already translated into 22 different languages and it has been wiedly used among different societies. Cronbach alpha was calculated as 0.93 for successful and 0.87 for unsuccessful entrepreneurs, which are well above the minimum required level.

\section{The results}

In this section, we present details of our survey for all categories of questions distributed among two groups of entrepreneurs. Table 1 shows the summary of our results.

\section{Table 1}

The summary of statistical figures

\begin{tabular}{lllllll}
\hline \multirow{2}{*}{ Title } & \multicolumn{3}{l}{ Successful entrepreneur } & \multicolumn{4}{c}{ unsuccessful entrepreneur } \\
\cline { 2 - 7 } & Max & Mean & $\%$ & Max & Mean & $\%$ \\
\hline Social commitment & 50 & 40.86 & 81.71 & 50 & 28.62 & 57.24 \\
Interpersonal relationships & 60 & 51.86 & 86.43 & 60 & 35.33 & 58.89 \\
Being independence & 35 & 29.14 & 83.27 & 35 & 16.95 & 48.43 \\
Self-actualization & 30 & 25 & 83.26 & 30 & 16.67 & 55.56 \\
Self-esteem & 30 & 25.95 & 86.51 & 30 & 18 & 60 \\
Self-awareness & 50 & 43.28 & 86.57 & 50 & 29.42 & 58.86 \\
Assertiveness & 45 & 37.90 & 84.23 & 45 & 24.33 & 54.07 \\
Optimism & 50 & 45.71 & 91.43 & 50 & 29.14 & 58.28 \\
Exhilaration & 50 & 40.95 & 81.90 & 35 & 19.43 & 55.51 \\
Impulse control & 35 & 29.28 & 83.67 & 40 & 22.81 & 57.24 \\
Stress tolerance & 40 & 33.67 & 84.17 & 50 & 31.19 & 52.38 \\
Flexibility & 45 & 38.86 & 86.34 & 45 & 26.67 & 59.26 \\
Being realistic & 60 & 50.714 & 84.52 & 60 & 33.43 & 55.72 \\
Problem solving & 50 & 42.047 & 84.09 & 50 & 28.95 & 57.9 \\
Empathy & 40 & 34.42 & 86.07 & 40 & 22.05 & 55.12 \\
\hline
\end{tabular}

In Table 1, we see the max, mean and percentage of responces for different items of the survey for both successful and unsuccessful entrepreneurs. In summary, the first group, the successful entrepreneurs, maintain an average of $84.95 \%$ on all questions while the second group only maintains $56.29 \%$, which means there is a meaningful difference between these two groups. In other words, it seems that successful entrepreneurs manage to have better EI compared with unsuccessful group. Table 2 shows details of our ANOVA test between two groups.

Table 2

The summary ANOVA test results (alpha $=0.05$ )

\begin{tabular}{lllllll}
\hline Source of Variation & SS & df & MS & F & P-value & F crit \\
\hline Between Groups & 6155 & 1 & 6155.02 & 817.82 & $2.88 \mathrm{E}-22$ & 4.19 \\
Within Groups & 210.8 & 28 & 7.53 & & & \\
\hline Total & 6365.8 & 29 & & & & \\
\hline
\end{tabular}


As we can observe from the results of ANOVA test, P-value is highly meaningful meaning that there is a significant difference between two groups when the level of significance is five percent. Therefore, all five hypotheses have been confirmed and we can conclude that there IE plays positive impact on the success on entrepreneurs. Fig. 2 shows the summary of our results for two groups.

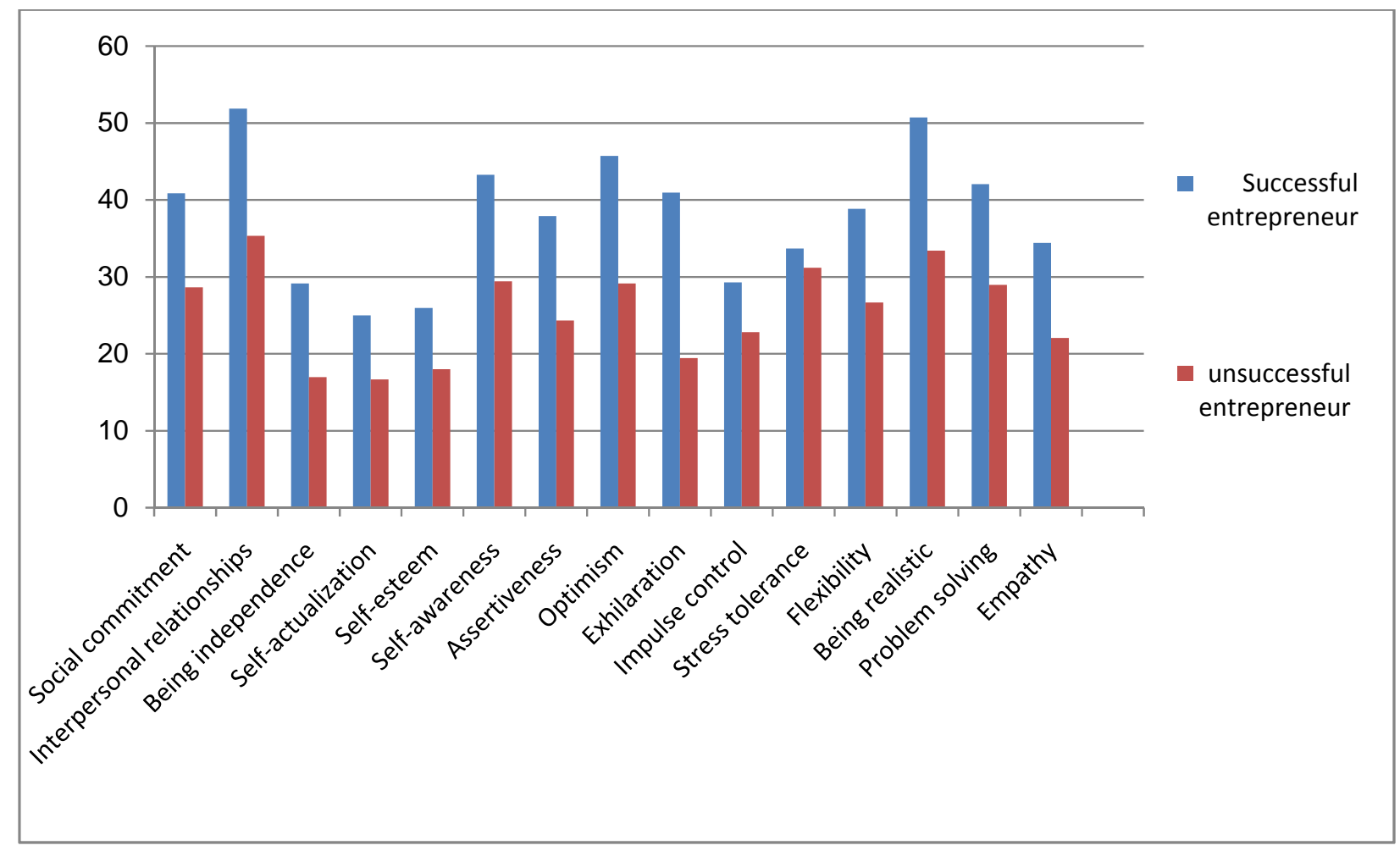

Fig. 2. The average responses for successful and unsuccessful entrepreneurs

As we can observe from the results of Fig. 2, successful entrepreneurs maintained much better interpersonal relationships; they were more realistic and have a great sense of optimism. The other components of our survey were relatively higher for successful group compared with unsuccessful group.

\section{Conclusion}

We have presented an empirical study to measure the impact of emotional intelligence and cognitive between successful and unsuccessful entrepreneurs. The study used a standard questionnaire, which used in many studies and in various societies. The questionnaire consisted of 133 different questions categorized in 15 groups. The primary objective was to understand whether improving entrepreneurs' EQ could help them succeed in their business plans. We have selected a sample of 42 people and chose two groups of successful and unsuccessful, both with equal size of 21 . The results of one-way ANOVA test yielded a meaningful difference between two groups, which confirmed all our hypotheses.

\section{Acknowledgment}

The authors would like to thank the anonymous referees for their insights on earlier version of this paper, which help us improve the quality of the paper. The authors also would like to thank the successful and unsuccessful entrepreneurs for cordially helping us accomplish our objectives. 


\section{References}

Ahmetoglu, G., Leutner, F., \& Chamorro-Premuzic, T. (2011). EQ-nomics: Understanding the relationship between individual differences in Trait Emotional Intelligence and entrepreneurship. Personality and Individual Differences, 51(8), 1028-1033.

Austin, E.J., Farrelly, D., Black, C., \& Moore, H. (2007). Emotional intelligence, Machiavellianism and emotional manipulation: Does EI have a dark side? Personality and Individual Differences, 43(1), 179-189.

Baron, R.A., Hmieleski, K.M., \& Henry, R.A. (2012). Entrepreneurs' dispositional positive affect: The potential benefits - and potential costs - of being "up". Journal of Business Venturing, 27(3), 310-324.

Byington, E., \& Felps, W. (2010). Why do IQ scores predict job performance?: An alternative, sociological explanation. Research in Organizational Behavior, 30, 175-202.

Brandstätter, H. (1997). Becoming an entrepreneur - A question of personality structure? Journal of Economic Psychology, 18(2-3), 157-177.

Cojocariu, V.M., \& Nechita, Z. (2011). On a Programme for Stimulating the Elementary Pupil's Emotional Intelligence through the Educational Process. Procedia - Social and Behavioral Sciences, 11, 261-265

Dacre Pool, L., \& Qualter, P. (2012). Improving emotional intelligence and emotional self-efficacy through a teaching intervention for university students. Learning and Individual Differences, 22(3), 306-312

Di Fabio, A., \& Palazzeschi, L. (2009). An in-depth look at scholastic success: Fluid intelligence, personality traits or emotional intelligence? Personality and Individual Differences, 46(5-6), 581585.

MacCann, C., Fogarty, G.J., Zeidner, M., \& Roberts, R.D. (2011). Coping mediates the relationship between emotional intelligence (EI) and academic achievement. Contemporary Educational Psychology, 36(1), 60-70.

Nelis, D., Quoidbach, J., Mikolajczak, M., \& Hansenne, M. (2009). Increasing emotional intelligence: (How) is it possible? Personality and Individual Differences, 47(1), 36-41 